\title{
PENYELESAIAN NUMERIK DARI PERSAMAAN DIFERENSIAL NONLINIER ADVANCE-DELAY
}

\author{
YOSI ASMARA \\ Program Studi Magister Matematika, \\ Fakultas Matematika dan Ilmu Pengetahuan Alam, Universitas Andalas, \\ Kampus UNAND Limau Manis Padang, Indonesia, \\ email : asmara.yosi@gmail.com
}

\begin{abstract}
Abstrak. Pada makalah ini akan dijelaskan tentang konstruksi skema numerik dalam menyelesaikan persamaan diferensial nonlinier advance-delay. Skema numerik menggunakan beda hingga untuk mengaproksimasi bagian turunan dari persamaan, dan interpolasi kubik untuk mengaproksimasi bagian advance-delay. Telah dibuktikan pula bahwa skema numerik tersebut konsisten terhadap persamaan advance-delay. Skema numerik yang dihasilkan diuji dengan solusi eksak yang telah diketahui. Berdasarkan hasil simulasi numerik yang dilakukan, dapat disimpulkan bahwa solusi numerik dari persamaan diferensial nonlinier advance-delay mempunyai kesesuaian yang sangat baik dengan solusi eksaknya.
\end{abstract}

Kata Kunci: Differential equations, initial value problem, heaviside

\section{Pendahuluan}

Persamaan diferensial banyak diterapkan dalam berbagai disiplin ilmu seperti fisika, kimia, biologi, metalurgi dan disiplin ilmu lainnya. Salah satu kelas dari persamaan diferensial adalah persamaan diferensial advance-delay, yaitu persamaan yang memuat nilai-nilai variabel tunda, misalkan $(t-\tau)$ dan variabel maju, misalkan $(t+\tau)$, dengan $\tau>0$.

Pada makalah ini akan dikaji penyelesaian numerik dari persamaan diferensial advance-delay yang berbentuk

$$
v^{\prime}(t)=v(t-\tau)-2 v(t)+v(t+\tau)+f(v(t)),
$$

dimana $t \in \mathbb{R}, \lim _{t \rightarrow-\infty} v(t)=0, \lim _{t \rightarrow+\infty} v(t)=1$, dan $f(v(t))$ menyatakan suku nonlinier.

Persamaan (1.1) juga dikenal sebagai persamaan diferensial bertipe campuran (mixed type). Persamaan advance-delay (1.1) diperkenalkan pertama kali oleh Chi dkk [2] pada tahun 1986 dengan membahas aplikasi pada masalah penghantaran rangsangan pada sistem jaringan syaraf. Selanjutnya pada tahun 1989, Rustichini [6] juga mengkaji persamaan advance-delay (1.1) dengan aplikasi pada masalah kontrol optimal untuk kasus autonomous linier. Rustichini kemudian memperluas kajiannya untuk kasus nonlinier dengan aplikasi pada masalah dinamika ekonomi [7].

Persamaan diferensial (advance-delay) juga dapat muncul dari masalah gelombang berjalan (traveling wave) pada media spasial diskrit (lattice). Sebagai ilustrasi, 
pandang persamaan diferensial lattice linier berikut:

$$
\dot{u}_{n}=u_{n+1}+u_{n-1}-2 u_{n},
$$

dimana $u_{n} \equiv u_{n}(t)$ dan $\dot{u}_{n} \equiv u_{n}^{\prime}(t)$. Solusi gelombang berjalan dari persamaan (1.2) dapat ditentukan dengan melakukan transformasi

$$
u_{n}(t)=v(z),
$$

dimana $z=n-k t$ dengan $k>0$ menyatakan parameter kecepatan. Selanjutnya, substitusi persamaan (1.3) ke persamaan (1.2) menghasilkan

$$
-k v^{\prime}(z)=v(z+1)+v(z-1)-2 v(z),
$$

yang merupakan persamaan diferensial advance-delay.

Dalam masalah gelombang berjalan pada media spasial diskrit nonlinier, persamaan advance-delay yang muncul pada masalah ini sulit untuk dianalisis [4]. Oleh karena itu pendekatan numerik sangat penting untuk dilakukan.

\section{Aproksimasi Solusi di Luar Interval}

Pandang kembali persamaan (1.1) dengan $f \in C^{3}[0,1]$ dan memenuhi $f(0)=0$, $f(1)=0, f^{\prime}(0)<0$, dan $f(1)<0$. Akan dicari solusi $v(t)$ yang monoton naik sedemikian sehingga $0<v(t)<1$ untuk setiap $t$. Dalam konteks numerik, persamaan (1.1) diselesaikan dalam interval tutup $t \in[-L, L]$ untuk suatu $L>0$ yang cukup besar. Karena adanya suku advance dan suku delay pada persamaan (1.1), maka perlu ditinjau aproksimasi solusi di luar interval $[-L, L]$, yaitu untuk $t<-L$ dan $t>L$.

Pandang terlebih dahulu kasus $t \leq-L$ dengan $v(t) \rightarrow 0$, dan $f(v(t)) \rightarrow 0$ ketika $t \rightarrow-\infty$. Dengan menggunakan ekspansi Taylor [1] untuk $f$ di sekitar $v(t)=0$, diperoleh

$$
f(v(t))=a_{1} v(t)+a_{2} v(t)^{2}+a_{3} v(t)^{3}+\mathcal{O}\left(v(t)^{4}\right) .
$$

Dengan demikian persamaan (1.1) dapat ditulis

$$
\begin{aligned}
v^{\prime}(t)=a_{1} v(t)+ & a_{2} v(t)^{2}+a_{3} v(t)^{3}+v(t-\tau)-2 v(t) \\
& +v(t+\tau)+\mathcal{O}\left(v(t)^{4}\right)
\end{aligned}
$$

Perhatikan bahwa

$$
v(-L)=\varepsilon u_{1}(-L)+\varepsilon^{2} u_{2}(-L)+\varepsilon^{3} u_{3}(-L)+\mathcal{O}(\varepsilon)^{4} .
$$

Oleh karena $\varepsilon=v(-L)$, maka digunakan syarat batas berikut:

$$
u_{1}(-L)=1, \quad u_{2}(-L)=0, \quad u_{3}(-L)=0 .
$$

Perhatikan bahwa persamaan (2.4) adalah persamaan linier homogen. Dengan demikian solusi persamaan (2.4) dapat diperoleh dengan mensubstitusikan $u_{1}(t)=$ $K e^{\lambda t}$, untuk suatu konstanta $K$, ke persamaan (2.4). Substitusi ini memberikan hasil berikut:

$$
\lambda-\left(a_{1}-2\right)-\left(e^{\lambda \tau}+e^{-\lambda \tau}\right)=0 \Longleftrightarrow \lambda+2-a_{1}-2 \cosh (\lambda \tau)=0 .
$$


Karena $a_{1}=f^{\prime}(0)<0$, maka persamaan (2.5) memiliki dua akar riil yang bernilai positif dan negatif. Misalkan $\lambda_{+}$adalah akar positif dari persamaan (2.5), maka solusi dari persamaan (2.4) yang memenuhi $u_{1}(-L)=1$ dan $u_{1}(t) \rightarrow 0$ ketika $t \rightarrow-\infty$ adalah

$$
u_{1}(t)=e^{\lambda_{+}(t+L)}
$$

Selanjutnya perhatikan bahwa persamaan (2.6) adalah persamaan linier nonhomogen. Misalkan solusi partikular dari persamaan (2.6) adalah $u_{2}^{p}(t)=b_{1} e^{2 \lambda_{+}(t+L)}$, sehingga setelah disubstitusikan ke persamaan (2.6) diperoleh

$$
b_{1}=\frac{a_{2}}{2 \lambda_{+}-a_{1}+2-2 \cosh \left(2 \lambda_{+} \tau\right)} .
$$

Dengan demikian solusi dari persamaan (2.6) yang memenuhi $u_{2}(-L)=0$ adalah

$$
u_{2}(t)=e^{\lambda+(t+L)}+b_{1} e^{2 \lambda_{+}(t+L)} .
$$

Kemudian perhatikan pula bahwa persamaan (2.7) adalah persamaan linier nonhomogen. Misalkan solusi partikular dari persamaan (2.7) adalah $u_{3}^{p}(t)=$ $b_{2} e^{2 \lambda_{+}(t+L)}+b_{3} e^{3 \lambda_{+}(t+L)}$, sehingga setelah disubstitusikan ke persamaan (2.7) diperoleh

$$
\begin{aligned}
& b_{2}=\frac{-2 a_{2} b_{1}}{2 \lambda_{+}-a_{1}+2-2 \cosh \left(2 \lambda_{+} \tau\right)}=-2 b_{1}^{2}, \\
& b_{3}=\frac{2 a_{2} b_{1}+a_{3}}{3 \lambda_{+}-a_{1}+2-2 \cosh \left(3 \lambda_{+} \tau\right)} .
\end{aligned}
$$

Dengan demikian solusi dari persamaan (2.7) adalah

$$
u_{3}(t)=e^{\lambda_{+}(t+L)}+b_{2} e^{2 \lambda_{+}(t+L)}+b_{3} e^{3 \lambda_{+}(t+L)} .
$$

Jadi untuk $t<-L$ didapatkan

$$
\begin{aligned}
& v(t)=\varepsilon e^{\lambda_{+}(t+L)}+\varepsilon^{2}\left(e^{\lambda_{+}(t+L)}+b_{1}\left(e^{2 \lambda_{+}(t+L)}\right)\right) \\
& +\varepsilon^{3}\left(e^{\lambda_{+}(t+L)}+b_{2} e^{2 \lambda_{+}(t+L)}+b_{3} e^{3 \lambda_{+}(t+L)}\right)+\mathcal{O}\left(\varepsilon^{4}\right) .
\end{aligned}
$$

Selanjutnya pandang kasus $t>L$, dengan $v(t) \rightarrow 1$ dan $f(v(t)) \rightarrow 0$ ketika $t \rightarrow+\infty$. Dengan menggunakan ekspansi Taylor di sekitar $v(t)=1$ diperoleh

$$
\begin{aligned}
f(v(t)) & =f(1)+f^{\prime}(1)(v(t)-1)+\frac{f^{\prime \prime}(1)}{2 !}(v(t)-1)^{2} \\
& +\frac{f^{\prime \prime \prime}(1)}{3 !}(v(t)-1)^{3}+\mathcal{O}\left((v(t)-1)^{4}\right) .
\end{aligned}
$$

Untuk penyederhanaan penulisan, misalkan

$$
A_{1}=-f^{\prime}(1), \quad A_{2}=-\frac{f^{\prime \prime}(1)}{2 !}, \quad A_{3}=-\frac{f^{\prime \prime \prime}(1)}{3 !} .
$$

Dengan menggunakan (2.11) dan dari kenyataan $f(1)=0$ maka persamaan (2.10) dapat ditulis menjadi

$$
\begin{gathered}
v^{\prime}(t)=A_{1}(1-v(t))+A_{2}(1-v(t))^{2}+A_{3}(1-v(t))^{3}+(v(t-\tau)) \\
-2 v(t)+v(t+\tau)+\mathcal{O}\left((1-v(t))^{4}\right) .
\end{gathered}
$$

Karena $v(L) \rightarrow 1$ ketika $L \rightarrow \infty$, maka tulis $v(L)=1-\varepsilon_{+}, 0<\varepsilon_{+} \ll 1$. Selanjutnya pandang ekspansi

$$
v(t)=1-\varepsilon_{+} w_{1}(t)-\varepsilon_{+}^{2} w_{2}(t)-\varepsilon_{+}^{3} w_{3}(t)+\mathcal{O}\left(\varepsilon_{+}^{4}\right) .
$$


100 Yosi Asmara

Perhatikan bahwa

$$
v(L)=1-\varepsilon_{+} w_{1}(L)-\varepsilon_{+}^{2} w_{2}(L)-\varepsilon_{+}^{3} w_{3}(L)+\mathcal{O}\left(\varepsilon_{+}^{4}\right) .
$$

Oleh karena $v(L)=1-\varepsilon_{+}$, maka digunakan syarat batas berikut:

$$
w_{1}(L)=1, \quad w_{2}(L)=0, \quad w_{3}(L)=0 .
$$

Substitusikan persamaan (2.13) ke persamaan (2.12), maka didapatkan

$$
\begin{aligned}
& 1+\left(-A_{1} w_{1}(t)-w_{1}^{\prime}(t)-2 w_{1}(t)+w_{1}(t-\tau)+w_{1}(t+\tau)\right) \varepsilon_{+} \\
& +\left(-A_{2} w_{1}(t)^{2}-A_{1} w_{2}(t)-w_{2}^{\prime}(t)-2 w_{2}(t)+w_{2}(t-\tau)+w_{2}(t+\tau)\right) \varepsilon_{+}^{2} \\
& +\left(-A_{3} w_{1}(t)^{3}-2 A_{2} w_{1}(t) w_{2}(t)-A_{1} w_{3}(t)-w_{3}^{\prime}(t)-2 w_{3}(t)+w_{3}(t-\tau)\right. \\
& \left.+w_{3}(t+\tau)\right) \varepsilon_{+}^{3}+\mathcal{O}\left(\varepsilon_{+}^{4}\right) .
\end{aligned}
$$

sehingga diperoleh persamaan-persamaan berikut:

$$
\begin{aligned}
& \mathcal{O}\left(\varepsilon_{+}\right): w_{1}^{\prime}(t)-K_{\tau} w_{1}(t)=0 \\
& \mathcal{O}\left(\varepsilon_{+}^{2}\right): w_{2}^{\prime}(t)-K_{\tau} w_{2}(t)=-A_{2} w_{1}(t)^{2} \\
& \mathcal{O}\left(\varepsilon_{+}^{3}\right): w_{3}^{\prime}(t)-K_{\tau} w_{3}(t)=-A_{2} w_{1}(t)^{3}-2 A_{2} w_{1}(t) w_{2}(t),
\end{aligned}
$$

dimana operator $K_{\tau}$ didefinisikan sebagai

$$
K_{\tau} w(t)=w(t-\tau)-\left(A_{1}+2\right) w(t)+w(t+\tau) .
$$

Perhatikan bahwa persamaan (2.16) adalah persamaan linier homogen. Solusi persamaan (2.16) dapat diperoleh dengan mensubstitusikan $u_{1}(t)=D e^{\lambda t}$, untuk suatu konstanta $D$, ke persamaan (2.16). Substitusi ini memberikan hasil

$$
\lambda-\left(A_{1}-2\right)-\left(e^{\lambda \tau}+e^{-\lambda \tau}\right)=0 \Leftrightarrow \lambda+2-A_{1}-2 \cosh (\lambda \tau)=0 .
$$

Persamaan (2.20) memiliki dua akar riil yang bernilai positif dan negatif, karena $A_{1}=-f^{\prime}(0)>0$. Misalkan $\lambda_{-}$adalah akar negatif dari persamaan (2.20), maka solusi dari persamaan (2.16) yang memenuhi $w_{1}(L)=1$ dan $w_{1}(t) \rightarrow 1$ ketika $t \rightarrow \infty$ adalah

$$
w_{1}(t)=e^{\lambda_{-}(t-L)} .
$$

Selanjutnya perhatikan bahwa persamaan (2.17) adalah persamaan linier nonhomogen. Misalkan solusi partikular dari persamaan (2.17) adalah $w_{2}^{p}(t)=$ $B_{1} e^{2 \lambda_{-}(t-L)}$, sehingga setelah disubstitusikan ke persamaan (2.17) diperoleh

$$
B_{1}=\frac{-A_{2}}{2 \lambda_{-}+\left(A_{1}+2\right)-2 \cosh \left(2 \lambda_{-}\right)} .
$$

Dengan demikian solusi dari persamaan (2.17) adalah

$$
w_{2}(t)=e^{\lambda_{-}(t-L)}+B_{1}\left(e^{2 \lambda_{-}(t-L)}\right) .
$$

Kemudian perhatikan pula bahwa persamaan (2.18) adalah persamaan linier nonhomogen. Misalkan solusi partikular dari persamaan (2.18) adalah $w_{3}^{p}(t)=$ 
$B_{2} e^{2 \lambda_{-}(t-L)}+B_{3} e^{3 \lambda_{-}(t-L)}$, sehingga setelah disubstitusikan ke persamaan (2.18), diperoleh

$$
\begin{aligned}
& B_{2}=\frac{2 A_{2} B_{1}}{2 \lambda_{-}+A_{1}+2-2 \cosh \left(2 \lambda_{-} \tau\right)}=-2 B_{1}^{2}, \\
& B_{3}=\frac{-2 A_{2} B_{1}-A_{3}}{3 \lambda_{-}+A_{1}+2-2 \cosh \left(3 \lambda_{-} \tau\right)} .
\end{aligned}
$$

Jadi solusi dari persamaan (2.18) adalah

$$
w_{3}(t)=e^{\lambda_{-}(t-L)}+B_{2} e^{2 \lambda_{-}(t-L)}+B_{3} e^{3 \lambda_{-}(t-L)} .
$$

Oleh karena itu, untuk $t>L$, dengan $\varepsilon_{+}=1-v(L)$ diperoleh

$$
\begin{gathered}
v(t)=1-\varepsilon_{+} e^{\lambda_{-}(t-L)}-\varepsilon_{+}^{2}\left(B_{1} e^{2 \lambda_{-}(t-L)}+e^{\lambda_{-}(t-L)}\right) \\
-\varepsilon_{+}^{3}\left(e^{\lambda_{-}(t-L)}+B_{2} e^{2 \lambda_{-}(t-L)}+B_{3} e^{3 \lambda_{-}(t-L)}\right)+\mathcal{O}\left(\varepsilon_{+}^{4}\right) .
\end{gathered}
$$

Substitusikan persamaan (2.3) ke persamaan (2.2), maka diperoleh

$$
\begin{aligned}
& \left(-a_{1} u_{1}(t)+u_{1}^{\prime}(t)+2 u_{1}(t)-u_{1}(t-\tau)-u_{1}(t+\tau)\right) \varepsilon+\left(-a_{2} u_{1}(t)^{2}\right. \\
& \left.-a_{1} u_{2}(t)+u_{2}^{\prime}(t)+2 u_{2}(t)-u_{2}(t-\tau)-u_{2}(t+\tau)\right) \varepsilon^{2}+\left(-a_{3} u_{1}(t)^{3}\right. \\
& \left.-2 a_{2} u_{1}(t) u_{2}(t)-a_{1} u_{3}(t)+u_{3}^{\prime}(t)+2 u_{3}(t)-u_{3}(t-\tau)-u_{3}(t+\tau)\right) \varepsilon^{3} \\
& +\mathcal{O}(\varepsilon)^{4}=0,
\end{aligned}
$$

sehingga didapatkan persamaan-persamaan berikut:

$$
\begin{aligned}
\mathcal{O}(\varepsilon): u_{1}^{\prime}(t)-L_{\tau} u_{1}(t) & =0, \\
\mathcal{O}\left(\varepsilon^{2}\right): u_{2}^{\prime}(t)-L_{\tau} u_{2}(t) & =a_{2} u_{1}(t)^{2}, \\
\mathcal{O}\left(\varepsilon^{3}\right): u_{3}^{\prime}(t)-L_{\tau} u_{3}(t) & =a_{3} u_{1}(t)^{3}+2 a_{2} u_{1}(t) u_{2}(t),
\end{aligned}
$$

dimana operator $L_{\tau}$ didefinisikan sebagai

$$
L_{\tau} u(t)=u(t-\tau)+\left(a_{1}-2\right) u(t)+u(t+\tau) .
$$

\section{Beda Hingga dan Skema Interpolasi}

Pandang persamaan diferensial advance-delay nonlinier berikut:

$$
\frac{d v(t)}{d t}=f(v(t))+v(t-\tau)-2 v(t)+v(t+\tau), \quad-L \leq t \leq L .
$$

Dalam hal ini $f$ adalah fungsi nonlinier dengan $f(0)=f(1)=0$. Persamaan (3.1) adalah persamaan autonomus, oleh karena itu ditetapkan

$$
v(0)=0.5 \text {. }
$$

Untuk menerapkan skema beda hingga pada persamaan (3.1), interval $[-L, L]$ dipartisi menjadi $N$ subinterval. Setiap subinterval mempunyai panjang yang sama, misalkan $h$. Jadi titik-titik partisi dapat ditulis $t_{j}=-L+j h, j=0,1,2, \cdots, N$, dimana $N=2 L / h$. Selanjutnya tulis nilai $v\left(t_{j}\right)$ dengan $v_{j}$. Suku turunan pertama dari persamaan (3.1) diaproksimasi dengan menggunakan beda pusat orde empat [3], yaitu diperoleh

$$
v^{\prime}(t)=\frac{1}{12 h}(v(t-2 h)-8 v(t-h)+8 v(t+h)-v(t+2 h))+\frac{h^{4}}{30} f^{(5)}(\zeta),
$$


untuk suatu $\zeta \in(t-2 h, t+2 h)$. Dengan demikian untuk $t=t_{j}$ didapatkan

$$
v^{\prime}\left(t_{j}\right)=\frac{1}{12 h}\left(v_{j-2}-8 v_{j-1}+8 v_{j+1}-v_{j+2}\right) .
$$

Perhatikan bahwa untuk $j=0$ dan $j=1$, suku $v_{-2}$ dan $v_{-1}$ muncul pada persamaan (3.4). Pada kasus ini digunakan persamaan (2.9) untuk mengaproksimasi $v_{-2}$ dan $v_{-1}$, yaitu pada saat $t=-L-2 h$ dan $t=-L-h$. Dengan cara yang sama, untuk $j=N-1$ dan $j=N$, suku $v_{N+1}$ dan $v_{N+2}$ muncul pada persamaan (3.4). Persamaan (2.24) kemudian digunakan untuk mengaproksimasi $v_{N+1}$ dan $v_{N+2}$, yaitu pada saat $t=L+h$ dan $t=L+2 h$.

Selanjutnya suku advance dan delay pada persamaan (3.1) diaproksimasi dengan menggunakan interpolasi kubik. Misalkan $M=[\tau / h]$, dimana " $[x]$ " menyatakan bagian dari bilangan bulat dari $x$ dan misalkan $r=\tau-M h$. Jelas bahwa $r \geq 0$ dan $t-M h-h<t-\tau<t-M h$. Dengan menggunakan formula kubik diperoleh

$$
\begin{aligned}
v(t-\tau)= & C_{4} v(t-M h-2 h)+C_{3} v(t-M h-h)+C_{2} v(t-M h) \\
& +C_{1} v(t-M h+h)+\frac{9 h^{4}}{342} f^{(4)}(\zeta),
\end{aligned}
$$

untuk suatu $\zeta \in(t-M h-2 h, t-M h+h)$, dimana $C_{i}$ adalah konstanta yang diberikan oleh

$$
\begin{aligned}
C_{1} & =\frac{-(2 h-r)(h-r) r}{6 h^{3}}, \\
C_{2} & =\frac{(2 h-r)(h-r)(h+r)}{2 h^{3}}, \\
C_{3} & =\frac{(2 h-r)(h+r) r}{2 h^{3}}, \\
C_{4} & =\frac{-(h+r)(h-r) r}{6 h^{3}} .
\end{aligned}
$$

Dengan demikian suku delay diaproksimasi oleh

$$
v\left(t_{j}-\tau\right) \approx C_{4} v_{j-M-2}+C_{3} v_{j-M-1}+C_{2} v_{j-M}+C_{1} v_{j-M+1} .
$$

Dengan cara yang sama, suku advance diaproksimasi oleh

$$
v\left(t_{j}+\tau\right) \approx C_{4} v_{j+M+2}+C_{3} v_{j+M+1}+C_{2} v_{j+M}+C_{1} v_{j+M-1} .
$$

Dengan menggunakan persamaan (3.2) sampai persamaan (3.6), maka persamaan (3.1) dapat ditulis dalam bentuk diskrit sebagai berikut:

$$
\begin{aligned}
\frac{1}{12 h}\left(v_{j-2}-8 v_{j-1}+8 v_{j+1}-v_{j+2}\right)-f\left(v_{j}\right)+2 v_{j}-C_{1} v_{j+M-1} & \\
-C_{2} v_{j+M}-C_{3} v_{j+M+1}-C_{4} v_{j+M+2}-C_{4} v_{j-M-2}-C_{3} v_{j-M-1} & \\
-C_{2} v_{j-M}-C_{1} v_{j-M+1} & =0,
\end{aligned}
$$

untuk $j=0,1, \cdots, N$.

Selanjutnya versi diskrit dari syarat (3.2) diberikan oleh

$$
v_{N^{\prime}}-0.5=0, \quad \text { dimana } N^{\prime}=[N / 2] .
$$

Untuk mendapatkan solusi numerik yang memenuhi syarat (3.2), maka persamaan ke- $[N / 2]$ pada sistem (3.7) diganti dengan persamaan (3.8). 


\section{Kekonsistenan Persamaan Beda}

Pada bagian ini akan diperiksa kekonsistenan dari persamaan beda (3.7) terhadap persamaan diferensial advance-delay (3.1) dengan menggunakan Definisi kekonsistenan [5]. Dengan menggunakan ekspansi deret Taylor di sekitar $v_{j}$, maka suku-suku pada persamaan beda (3.7) dapat ditulis:

$$
\begin{aligned}
v_{j \pm 2} & =v\left(t_{j}\right) \pm 2 h v^{\prime}\left(t_{j}\right)+2 h^{2} v^{\prime \prime}\left(t_{j}\right) \pm \frac{4}{3} h^{3} v^{\prime \prime \prime}\left(t_{j}\right)+\cdots \\
v_{j \pm 1} & =v\left(t_{j}\right) \pm h v^{\prime}\left(t_{j}\right)+\frac{1}{2} h^{2} v^{\prime \prime}\left(t_{j}\right) \pm \frac{1}{6} h^{3} v^{\prime \prime \prime}\left(t_{j}\right)+\cdots \\
v_{j \pm(M+1)} & =v\left(t_{j}\right) \pm(M+1) h v^{\prime}\left(t_{j}\right)+\frac{1}{2}((M+1) h)^{2} v^{\prime \prime}\left(t_{j}\right) \pm \frac{1}{6}((M+1) h)^{3} v^{\prime \prime \prime}\left(t_{j}\right)+\cdots \\
v_{j \pm(M+2)} & =v\left(t_{j}\right) \pm(M+2) h v^{\prime}\left(t_{j}\right)+2((M+2) h)^{2} v^{\prime \prime}\left(t_{j}\right) \pm \frac{4}{3}((M+2) h)^{3} v^{\prime \prime \prime}\left(t_{j}\right)+\cdots \\
v_{j \pm M} & =v\left(t_{j}\right) \pm M h v^{\prime}\left(t_{j}\right)+\frac{1}{2}(M h)^{2} v^{\prime \prime}\left(t_{j}\right) \pm \frac{1}{6}(M h)^{3} v^{\prime \prime \prime}\left(t_{j}\right)+\cdots \\
v_{j \pm(M-1)} & =v\left(t_{j}\right) \pm(M-1) h v^{\prime}\left(t_{j}\right)+\frac{1}{2}((M-1) h)^{2} v^{\prime \prime}\left(t_{j}\right) \pm \frac{1}{6}((M-1) h)^{3} v^{\prime \prime \prime}\left(t_{j}\right)+\cdots
\end{aligned}
$$

Substitusikan persamaan di atas ke persamaan beda (3.7) dan gunakan $r=\tau-M h$, diperoleh persamaan diferensial termodifikasi

$$
\left.\left(v^{\prime}\left(t_{j}\right)-f\left(v\left(t_{j}\right)\right)\right)+2 v\left(t_{j}\right)-v\left(t_{j}-\tau\right)-v\left(t_{j}+\tau\right)\right)+\mathcal{O}\left(h^{2}\right)=0 .
$$

\section{Simulasi Numerik}

Simulasi numerik pada subbab ini bertujuan untuk membandingkan solusi numerik dan solusi eksak dari persamaan (3.1). Sebagai contoh ilustrasi, digunakan suku nonlinier $f$ berikut:

$$
f(v)=\frac{1+2 \vartheta(2 v-1)-(1+\vartheta)(2 v-1)^{2}-\vartheta(3-2 v)(2 v-1)^{3}}{2\left(1-\vartheta(2 v-1)^{2}\right)},
$$

dengan $\tau=\tanh ^{-1}(\sqrt{\vartheta})$. Solusi eksak dari persamaan (3.1) dengan suku nonlinier (5.1) diberikan oleh [4]

$$
v(t)=\frac{1+\tanh (t)}{2}
$$

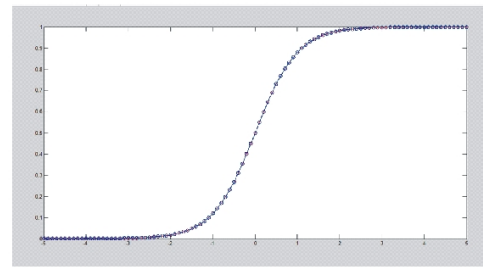

Gambar 1. Perbandingan solusi numerik (garis-bulat) dan solusi eksak (garis-silang) 
Dengan menggunakan parameter $\tau=1, h=0.1$ dan $L=5$, diperoleh hasil perbandingan antara solusi numerik dari persamaan diferensial nonlinier advancedelay (1.1) dengan solusi eksak (5.2), sebagaimana yang diberikan pada Gambar 1. Dari Gambar 1 dapat dilihat bahwa terdapat kesesuaian yang sangat baik antara solusi eksak dengan solusi numeriknya.

\section{Daftar Pustaka}

[1] Bartle, Robert G., Donald R. Sherbert. 2011. Introduction to Real Analysis. Edisi ke-4. John Wiley and Son, Urbana-Champaign.

[2] Chi, Henjin., Jonathan, Bell dan Brian, Hassard. 1986. Numerical Solution of A Nonlinear Advance-Delay-Differential Equation from Nerve Conduction Theory. J. Math Biol., 4: $583-601$.

[3] Mathews, John H., K. D. Fink. 1992. Numerical Methods for Computer Science, Engineering, and Mathematics. Edisi ke-2. Prentice-Hall, Englewood Cliffs.

[4] Melvin, T.R.O, dkk. 2007. Travelling solitary waves in the discrete Schrödinger equation with saturable nonlinearity: Existence, stability and dynamics. ScienceDirect.

[5] Pudjaprasetya, Sri Redjeki. 2009. Diktat Kuliah Persamaan Diferensial, Institut Teknologi Bandung. Bandung.

[6] Rustichini, A. 1989. Functional Differential Equations of Mixed Type. Journal of Dynamics and Differential Equations, 1: 121 - 143.

[7] Rustichini, A. 1989. Hopf Bifurcation for Functional Differential Equations of Mixed Type. Journal of Dynamics and Differential Equations, 1: 145 - 177. 